\title{
Comparison of the effect of two anti-adhesion materials on the formation of postoperative adhesions after myomectomy - an experimental study on rabbit does
}

\author{
Soňa Pánková1, Andrea Nečasová ${ }^{2}, J_{a n a}$ Lorenzová ${ }^{2}$, Vladimír Jekl ${ }^{3}$, Alois Nečas ${ }^{2}$, \\ Ladislav Dušek ${ }^{4}$, Robert Hudeček ${ }^{1}$, Petr Gál ${ }^{5}$
}

\begin{abstract}
${ }^{1}$ Brno University Hospital and Masaryk University Medical School, Department of Obstetrics and Gynaecology, Brno, Czech Republic

${ }^{2}$ University of Veterinary Sciences Brno, Faculty of Veterinary Medicine, Department of Surgery \& Orthopaedics, Small Animal Clinic, Brno, Czech Republic

${ }^{3}$ University of Veterinary Sciences Brno, Faculty of Veterinary Medicine, Department of Pharmacology and Pharmacy, Brno, Czech Republic

${ }^{4}$ Masaryk University, Faculty of Medicine, Institute of Biostatistics and Analyses, Brno, Czech Republic

${ }^{5}$ Masaryk University, Faculty of Medicine, Department of Pediatric Surgery, Orthopedics and Traumatology, Brno, Czech Republic
\end{abstract}

Received August 30, 2021

Accepted November 9, 2021

\begin{abstract}
This study compares the effect of Hyalobarrier Gel and 4DryField ${ }^{\circledR} \mathrm{PH}$ on the formation of postoperative adhesions after myomectomy in an experimental study on rabbit does. Thirty experimental animals were divided into three groups: group A - control, group B - use of 4DryField ${ }^{\circledR} \mathrm{PH}$, and group $\mathrm{C}$ - use of the Hyalobarrier Gel. A simulated myomectomy was performed in each group. The animals were euthanised 14 days after the procedure and the antiadhesive effect of the above-mentioned preparations was evaluated according to the criteria. Statistical evaluation clearly showed differences in the antiadhesive effect in the scoring systems for groups B and C compared to control group A at a high level of significance. We demonstrated an obvious, statistically confirmed antiadhesive effect of the Hyalobarrier Gel and 4DryField ${ }^{\circledR} \mathrm{PH}$ in an experimental model of the rabbit uterus. Comparing both preparations, the Hyalobarrier Gel shows a higher level of effectiveness. Based on the results of the experiment, both preparations can be unambiguously recommended for routine practice.
\end{abstract}

Lagomorpha, gynaecology, Hyalobarrier Gel, 4 DryField ${ }^{\circledR}$ PH

In human medicine, postoperative adhesions represent not just a serious clinical and social condition but also an economic problem. They occur after up to $60 \%$ of surgical procedures in the abdominal cavity, although with varying degrees of severity of consequences (Herrmann and De Wilde 2016). Additionally, they can directly or indirectly cause complications such as severe chronic pain, organ dysfunction, ileal condition, dyskinesia, etc., which compromise the quality of life of patients. There is also evidence that they significantly increase the risk of death after surgery (van den Beukel et al. 2017). They are often the cause for "repeated surgery", i.e. adhesiolysis aimed at disrupting these adhesions, which means they represent a significant financial burden for the health care complex and increase the social costs associated with early mortality in the long run (Sikirica et al. 2011). This issue also concerns veterinary surgery where the subject of postoperative adhesions has been described mainly in horses and rabbits experiencing a gradual expansion of breeding and the need to neuter them (Johnston 2005; Gorvy et al. 2008; Rizzo et al. 2010).

The rabbit uterus duplex model is often used in experimental surgery for the relative availability of the experimental animal, favourable anatomical conditions, and frequent

Address for correspondence:

MVDr. Andrea Nečasová

Department of Surgery \& Orthopaedics

Small Animal Clinic

Faculty of Veterinary Medicine

University of Veterinary and Pharmaceutical Sciences Brno

Palackého tř. 1946/1, 61242 Brno, Czech Republic 
postoperative adhesions (Dunn et al. 2001; Müller et al. 2011). Therefore, an experimental study was performed, comparing the antiadhesive effect of the Hyalobarier Gel (Anika Therapeutics S.r.l. Hyalobarrier gel, Padova, Italy) and 4DryField ${ }^{\circledR}$ PH (4DryField; PlantTec Medical GmbH, Lüneburg, Germany) after simulated myomectomy that we did not find in the available literature on a rabbit uterus duplex model.

\section{Materials and Methods}

The experiment was performed on an animal model - domestic rabbit (Oryctolagus cuniculus) doe, broiler hybrid HYPLUS, aged 4 months, a total of 30 animals. The housing of the animals and the follow-up of the experiment were carried out on the approved premises of the University of Veterinary Sciences Brno and performed in accordance with the planned project of the experiment. All rabbits were housed individually, provided with the same nutrition (complete granulated mixture for rabbits) and automatic drinkers with ad libitum water supply, all in compliance with welfare requirements. Observing the principles of 3R, the appropriate number of animals for each group was chosen so that it was possible to perform a statistical evaluation - a total of 3 groups of 10 animals.

Before the experiment, the animals were acclimatized for 12 days, during which they were preventively administered sulphadimidine sodium (Sulfadimidin BIOVETA $20 \mathrm{~g}, 20 \mathrm{~g}$ per 51 of water, Bioveta, Ivanovice na Hané, Czech Republic) in drinking water according to the following regimen: 3 days of administration of the treatment solution, 3 days water and then 3 days again administration of the treatment solution. After the acclimatization phase, the experiment was started under general anaesthesia. To induce anaesthesia, a combination of ketamine $50 \mathrm{mg} / \mathrm{kg}$ (Narkamon $100 \mathrm{mg} / \mathrm{ml}$ solution for injection, Bioveta) and xylazine $5 \mathrm{mg} / \mathrm{kg}$ (Rometar $20 \mathrm{mg} / \mathrm{ml}$ solution for injection, Bioveta) was administered intramuscularly (i.m.); anaesthesia was maintained by inhalation of a mixture of oxygen and 1.5-2\% isoflurane (Isofuran, Torrex Chiesi, Praha, Czech Republic). Prior to surgery, metamizole $25 \mathrm{mg} / \mathrm{kg}$ (Vetalgin $500 \mathrm{mg} / \mathrm{ml}$ inj., Intervet, Boxmeer, The Netherlands), metoclopramide $0.5 \mathrm{mg} / \mathrm{kg}$ (Degan $10 \mathrm{MG}$ solution for injection, Lek Pharmaceuticals, Ljubljana, Slovenia) and marbofloxacin $10 \mathrm{mg} / \mathrm{kg}$ (Marbocyl $100 \mathrm{mg} / \mathrm{ml}$ inj., Vétoquinol, Nymburk, Czech Republic) were administered i.m. Once the animal was anaesthetized, the ventral half of the abdominal wall was shaved from the sternum to the pelvic symphysis. The surgical area was washed with a povidone-iodine solution and disinfected with chlorhexidine. Furthermore, a caudal laparotomy was performed in the linea alba by making a laparotomy incision of about $4 \mathrm{~cm}$. Both uteri were gradually pulled into the surgical wound and the procedure was performed accordingly:

Group A (control group): Abrasion of the serous layer in the middle part of the left uterine horn with a range of about $4 \mathrm{~cm}$ was performed with a scalpel blade size 10 until bleeding was induced. Subsequently, a longitudinal incision of the uterine wall (approximately $3 \mathrm{~cm}$ ) was made at the site of the previous traumatization completely penetrating the uterine wall (myomectomy simulation) and subsequently sutured with a continuous stitch using a 1.5 USP polyfilament absorbable material (Vicryl, Ethicon, Somerville, United States) (Plate V, Figs 1 A, B, C, D, E, F).

Group B: Same as Group A + the use of 4DryField ${ }^{\circledR}$ PH (Plate VI, Figs 2, A, B, C, D).

Group C: Same as Group A + the use of the Hyalobarrier Gel (Plate VI, Figs 3 A, B, C, D).

Following the above procedures, a laparotomy wound suture was performed of the abdominal wall with a continuous suture pattern using an absorbable polyfilament material size 2 USP (Vicryl) and a subcutaneous suture with a continuous mattress suture pattern using an absorbable polyfilament material size 2 USP (Vicryl). All operations were performed by the same surgeon. After the procedure, the rabbits were monitored regularly, clinical examination was carried out daily, the surgical wound was inspected, and food intake and faecal excretion were assessed. After surgery, the animals were administered metamizole $25 \mathrm{mg} / \mathrm{kg}$ and metoclopramide $0.5 \mathrm{mg} / \mathrm{kg}$ i.m. twice daily for 3 days. Fourteen days aftersurgery, euthanasia wasperformed legeartisby intramuscularadministration of a combination of ketamine $50 \mathrm{mg} / \mathrm{kg}$ and xylazine $5 \mathrm{mg} / \mathrm{kg}$ followed by thiopental overdose i.v. (Thiopental VUAB 0.5 g inj plv sol., i.v., VUAB Pharma, Roztoky, Czech Republic). Before surgery and euthanasia, the animals were weighed, blood was collected from a. auricularis centralis, and a biochemical and haematological examination of the blood was carried out. After euthanasia, an autopsy was performed during which adhesion evaluation was conducted. The evaluation was performed by two independent evaluators according to predetermined criteria of modified scoring systems, namely: More Comprehensive Adhesion Scoring Method (MCASM) (Mettler 2003) and Peritoneal Adhesion Index (PAI) (Coccolini et al. 2013) (Tables 1,2) and the results were statistically evaluated.

The working hypotheses to be confirmed in this study are presented in Table 3 .

\section{Results}

The statistical evaluation clearly showed differences in the antiadhesive effect in the scoring systems for groups $\mathrm{B}$ and $\mathrm{C}$ compared to control group $\mathrm{A}$ at a high level of significance $(P<0.001)$. For better clarity, the results of the experiment are presented in individual tables that also describe the evaluation criteria. For illustration, images 
documenting the evaluation are attached. The evaluation of the antiadhesive effect of individual preparations is given in Table 4.

Statistical evaluations using Mann Whitney and Fisher's exact test are given in Tables 5 and 6. For better clarity, Figs 4 and 5 (Plate VII) show the basis for the evaluation.

Out of postoperative complications, we recorded only two dehiscences of the subcutaneous tissue that required only local treatment. We did not observe a purulent subperitoneal process in any animal.

Table 1. More Comprehensive Adhesion Scoring Method (MCASM) according to Mettler (2003).

\begin{tabular}{lll}
\hline & 0 & No adhesion present \\
Severity & 1 & Filmy, avascular \\
& 2 & Some vascularity and/or dense \\
& 3A & Cohesive, can be separated by minimal dissection \\
& 3B & Cohesive, can be separated by extensive dissection for separation \\
\hline \multirow{2}{*}{ Extent } & 0 & No adhesion present \\
& 1 & Mild ( $\leq 25 \%$ total area length) \\
& 2 & Moderate $(25-50 \%$ total area length $)$ \\
& 3 & Severe $(\geq 51 \%$ total area length)
\end{tabular}

Table 2. Peritoneal adhesion index (PAI) according to Coccolini et al. (2013).

\begin{tabular}{ll}
\hline Adhesion grade score \\
\hline 0 & No adhesion \\
1 & Filmy adhesions, blunt dissection \\
2 & Strong adhesion, sharp dissection \\
3 & Very strong vascularized adhesion, sharp dissection, damage hardly preventable \\
\hline
\end{tabular}

Table 3. Working hypotheses.

\begin{tabular}{ll}
\hline Hypothesis A & Hyalobarrier Gel reduces or blocks the formation of adhesions after myomectomy simulation \\
Hypothesis B & 4DryField ${ }^{\circledR} \mathrm{PH}$ reduces or blocks the formation of adhesions after myomectomy simulation \\
Hypothesis C & Hyalobarrier Gel is more effective than 4 DryField ${ }^{\circledR} \mathrm{PH}$ in the experiment
\end{tabular}

Table 4. SCORE according to evaluation criteria in individual groups.

\begin{tabular}{|c|c|c|c|c|c|c|c|c|}
\hline \multicolumn{3}{|c|}{ Group A - control } & \multicolumn{3}{|c|}{ Group B - 4DryField ${ }^{\circledR} \mathrm{PH}$} & \multicolumn{3}{|c|}{ Group C - Hyalobarrier Gel } \\
\hline Animal & PAI & $\overline{\text { MCASM }}$ & Animal & PAI & $\overline{\mathrm{MCASM}}$ & Animal & PAI & $\overline{M C A S M}$ \\
\hline 1 & 9 & 5 & 11 & 2 & 3 & 21 & 1 & 2 \\
\hline 2 & 8 & 5 & 12 & 2 & 3 & 22 & 1 & 2 \\
\hline 3 & 6 & 5 & 13 & 2 & 3 & 23 & 1 & 2 \\
\hline 4 & 8 & 5 & 14 & 1 & 2 & 24 & 0 & 0 \\
\hline 5 & 4 & 5 & 15 & 1 & 2 & 25 & 0 & 0 \\
\hline 6 & 6 & 4 & 16 & 2 & 3 & 26 & 0 & 0 \\
\hline 7 & 6 & 4 & 17 & 1 & 2 & 27 & 0 & 0 \\
\hline 8 & 6 & 4 & 18 & 1 & 2 & 28 & 0 & 0 \\
\hline 9 & 4 & 4 & 19 & 3 & 4 & 29 & 0 & 0 \\
\hline 10 & 8 & 4 & 20 & 3 & 4 & 30 & 0 & 0 \\
\hline
\end{tabular}

PAI - Peritoneal Adhesion Index; MCASM - More Comprehensive Adhesion Scoring Method 
Table 5. Statistical analysis of adhesion evaluation using the Peritoneal Adhesion Index (PAI) scoring system.

\begin{tabular}{|c|c|c|c|c|c|c|}
\hline \multirow[t]{2}{*}{$\begin{array}{l}\text { Summary } \\
\text { statistics }\end{array}$} & \multirow{2}{*}{$\begin{array}{l}\text { Control } \\
\text { A } \\
(n=10)\end{array}$} & \multirow{2}{*}{$\begin{array}{l}\text { Experiment: } \\
\qquad \text { Arm B } \\
(\mathrm{n}=10)\end{array}$} & \multirow{2}{*}{$\begin{array}{l}\text { Experiment: } \\
\text { Arm C } \\
(\mathrm{n}=10)\end{array}$} & \multicolumn{3}{|c|}{$\begin{array}{l}\text { Statistical significance } \\
\text { ( } P \text { value })\end{array}$} \\
\hline & & & & A vs. B & A vs. C & B vs. C \\
\hline Mean (SE) & $6.5(0.54)$ & $1.8(0.25)$ & $0.3(0.15)$ & & & \\
\hline Median & 6 & 2 & 0 & $<0.001$ & $<0.001$ & $<0.001$ \\
\hline Min/Max & $4 / 9$ & $1 / 3$ & $0 / 1$ & & & \\
\hline Value $\leq 1(\%)$ & $0(0.0 \%)$ & $4(40.0 \%)$ & $10(100.0 \%)$ & 0.087 & $<0.001$ & 0.011 \\
\hline Value $\geq 8(\%)$ & $4(40.0 \%)$ & $0(0.0 \%)$ & $0(0.0 \%)$ & 0.087 & 0.087 & - \\
\hline \multicolumn{7}{|l|}{ Ratio } \\
\hline Range/median & 0.83 & 1.00 & - & \multirow{4}{*}{\multicolumn{3}{|c|}{$\begin{array}{l}\text { Statistical significance was evaluated using } \\
\text { Mann Whitney U test for continuous variables } \\
\text { and Fisher exact test for categorical variables. }\end{array}$}} \\
\hline Ratio & & & & & & \\
\hline Range/mean & 0.77 & 1.11 & 3.33 & & & \\
\hline \multicolumn{4}{|l|}{ Ratio } & & & \\
\hline $\mathrm{SD} /$ mean & 0.26 & 0.44 & 1.61 & & & \\
\hline
\end{tabular}

Table 6. Statistical analysis of adhesion evaluation using More Comprehensive Adhesion Scoring Method (MCASM) scoring system.

\begin{tabular}{|c|c|c|c|c|c|c|}
\hline \multirow[t]{2}{*}{$\begin{array}{l}\text { Summary } \\
\text { statistics }\end{array}$} & \multirow{2}{*}{$\begin{array}{l}\text { Control } \\
\text { A } \\
(n=10)\end{array}$} & \multirow{2}{*}{$\begin{array}{l}\text { Experiment: } \\
\text { Arm B } \\
(\mathrm{n}=10)\end{array}$} & \multirow{2}{*}{$\begin{array}{l}\text { Experiment: } \\
\qquad \text { Arm C } \\
(\mathrm{n}=10)\end{array}$} & \multicolumn{3}{|c|}{$\begin{array}{l}\text { Statistical significance } \\
\text { ( } P \text { value })\end{array}$} \\
\hline & & & & A vs. B & A vs. C & B vs. C \\
\hline$\overline{\text { Mean }(\mathrm{SE})}$ & $4.5(0.17)$ & $2.8(0.25)$ & $0.6(0.31)$ & & & \\
\hline Median & 5 & 3 & 0 & $<0.001$ & $<0.001$ & $<0.001$ \\
\hline $\operatorname{Min} / \operatorname{Max}$ & $4 / 5$ & $2 / 4$ & $0 / 2$ & & & \\
\hline Value $\leq 1(\%)$ & $0(0.0 \%)$ & $0(0.0 \%)$ & $7(70.0 \%)$ & - & 0.003 & 0.003 \\
\hline Value $\geq 4(\%)$ & $10(100.0 \%)$ & $2(20.0 \%)$ & $0(0.0 \%)$ & 0.001 & $<0.001$ & 0.474 \\
\hline \multicolumn{7}{|l|}{ Ratio } \\
\hline Range/median & 0.22 & 0.67 & - & \multirow{4}{*}{\multicolumn{3}{|c|}{$\begin{array}{l}\text { Statistical significance was evaluated using } \\
\text { Mann Whitney U test for continuous variables } \\
\text { and Fisher exact test for categorical variables. }\end{array}$}} \\
\hline Ratio & & & & & & \\
\hline Range/mean & 0.22 & 0.71 & 3.33 & & & \\
\hline Ratio & & & & & & \\
\hline $\mathrm{SD} /$ mean & 0.12 & 0.28 & 1.61 & & & \\
\hline
\end{tabular}

\section{Discussion}

The development of adhesions after gynaecological surgeries is a serious problem. Minimising the invasiveness of surgical techniques and implementation of complex pharmacotherapy has proved insufficient as demonstrated on large patient populations in clinical practice. Therefore, new products that form an absorbable antiadhesive barrier at the surgical area are continuously being developed, having a widespread application (Vidas et al. 2018; Hu et al. 2021).

Experimental studies using hyaluronic acid derivatives in different variations and under different brand names on a model of the rabbit uterus are quite common. The results of these studies are generally consistent with our statistically confirmed conclusion regarding the potent antiadhesive effect of the Hyalobarrier Gel (Osada et al. 1999).

Other preparations with antiadhesive properties have been also examined using a model of the rabbit uterus, demonstrating the efficacy of phospholipids in reducing primary 
adhesion formation compared to hyaluronic acid-carboxymethylcellulose, lactidecaprolactone copolymer, and isodextrin (Müller et al. 2005).

In order to assess the work on a model of the rabbit uterine horn, a beneficial study examining the suture strength and the association between the suture material and adhesion formation after the use of fibrin sealant determined that such association was not significant and did not affect the suture strength (Peacock et al. 2006). A rare experiment was performed in a study concerned with the effect of hyaluronic acid on spontaneous fertility after repeated intrauterine surgeries with induced experimental synechiae in a rabbit model, where the animals underwent double curettage followed by a hyaluronic acid injection into one uterine horn. After the recovery period, the rabbits were mated. An abdominal ultrasound performed 21 days after the mating diagnosed pregnancy and quantified the number of viable foetuses. The authors consider this model to be an experimental one that can be used to study the efficacy of different preparations (Huberlant et al. 2015).

Some human medicine-related studies report that the formation of adhesions is caused by the effects of laparoscopy and port introduction (Monnet 2019). In an experiment involving rabbits, this theory was confirmed as adhesions formed in more than $50 \%$ of cases. These were adhesions to the anterior abdominal wall and the bladder (Balbinotto et al. 2010).

In the literature, we also found a combined study of antiadhesive preparations involving two animal models, rats and rabbits. The end-to-end intestinal anastomosis was performed and its strength and formation of adhesions were examined. It was discovered that adhesion formation was inhibited by the Spray Gel (polyethylene glycol), but only in the case of optimal healing of the anastomosis. However, when dehiscence and inflammation of the anastomosis occurred, multiple adhesions were observed (Dunn et al. 2001). Determining the right bowel anastomosis technique in terms of antiadhesion is very important in both veterinary and human medicine (Crha et al. 2008; Ntourakis et al. 2016). The antiadhesive effect of hyaluronic acid derivatives is often investigated in other indications, such as pericardial adhesions (Kang et al. 2015), when performing surgery for glaucoma (Takeuchi et al. 2009) or in combination with stem cells during regeneration of the trachea (Choi et al. 2021).

To date, we have not found any experimental study involving rabbits using 4DryField ${ }^{\circledR}$ $\mathrm{PH}$ in the available literary sources. Some experiments were conducted on an optimized peritoneal adhesion model on rats (OPAM). The effects of 4DryField ${ }^{\circledR} \mathrm{PH}$ and Arista on the formation of peritoneal adhesions were compared. It was found that only 4DryField ${ }^{\circledR}$ PH was significantly effective (Poehnert et al. 2019). The same model also showed the effect of the 4DryField ${ }^{\circledR} \mathrm{PH}$ in blocking the formation of adhesions into the intraperitoneal onlay meshes (IPOM) where adhesions are formed after hernia surgery and can cause serious medical complications (Winny et al. 2016). Another study compared the effects of Adept $\left({ }^{\circledR}\right)$, Interceed $\left({ }^{\circledR}\right)$, Seprafilm $\left({ }^{\circledR}\right)$, and 4DryField ${ }^{\circledR}$ PH (Poehnert et al. 2016). When it comes to the use of 4 DryFied $^{\circledR} \mathrm{PH}$, the authors discuss whether it is better to mix the gel beforehand or to make the gel directly in the surgical wound. Again, the 4DryField ${ }^{\circledR}$ PH most significantly reduced the rate of formation of new adhesions. No differences between gel preparations at different stages were statistically determined (Poehnert et al. 2016). The studies also evaluated in vitro cytotoxicity/biocompatibility as well as in vivo tolerability of the new polysaccharide 4 DryField $^{\circledR} \mathrm{PH}$, which was rated as excellent (Poehnert et al. 2015). Several studies using this preparation have been conducted in clinical medicine (Rudolph et al. 2019; Lucas et al. 2021). In the field of gynaecology, the antiadhesive effect of 4 DryField ${ }^{\circledR} \mathrm{PH}$ was evaluated in a clinical trial. The degree and extent of the adhesions were significantly reduced by $85 \%$ in the 4 DryField ${ }^{\circledR} \mathrm{PH}$ group compared to the control group (the mean overall adhesion score of $2.2 \mathrm{vs.} 14.2 ; P=0.004$ ) in female patients after endometriosis surgery (Krämer et al. 2021). A study concerning 
the post-operative treatment of uterine adhesions (Korell 2014) and open adhesiolysis produced similar results (Blumhardt et al. 2018).

Based on the results of our study together with a study of literary sources, some issues can be raised for discussion. There is no significant difference in terms of scoring systems for evaluation of the studies as they all describe the problem approximately equally and are universally applicable outside the gynaecological scope. The time of euthanasia of the animal, as well as the evaluation of the experiment are also questionable. Generally, adhesions occur most commonly between days 5-7 after the procedure and then they mature. The antiadhesive barrier of the preparations should be effective for the same time period. Fourteen days after the procedure we found no macroscopically noticeable product residues. The possibility of repeated laparoscopic monitoring of the development of adhesions in rabbits appears to be beneficial, although laparoscopy itself may also be the cause of their development. In the model, the technique and quality of the potential suture, as well as properly chosen anti-adhesive material, are also important. Due to the rapid growth and restlessness of laboratory animals, careful suture of the subcutaneous tissue and skin needs to be performed, and it can be recommended to supplement it with resuturing by individual stitches. From a technical perspective, both preparations are easy to use in open surgery. 4DryField ${ }^{\circledR} \mathrm{PH}$ has a major haemostatic effect which is an important antiadhesive factor. A study model of the uterus duplex in the rabbit is, in our opinion, suitable for examining other preparations. Besides macroscopic observation, the monitoring of biochemical and haematological indices, and their subsequent inclusion in the results is also advisable (Pecin et al. 2017; Urbanová et al. 2019).

Besides the development of antiadhesive barrier preparations, studies of molecular causes of adhesions and the potential to influence them, for example, with the use of a blockade of local angiotensin II/angiotensin II type 1 receptors (AngII/AT1R) will become increasingly important in the future (Tavakkoli et al. 2021). Gene therapy is another option, where the possibility of affecting the tissue plasminogen activator, tissue metalloproteinase inhibitor and transforming growth factor $\beta$, and genetic polymorphism in interleukin- 1 receptor antagonist, etc. (Atta 2011) is being investigated. However, other factors that influence the development of adhesions indirectly, such as diabetes mellitus, metabolic syndrome, hyperglycaemia, obesity, depression, excessive alcohol consumption, anti-parkinsonian drugs, oral hormone therapy, pregnancy, and malignant processes should also be borne in mind (Fortin et al. 2015).

This experimental study aimed to verify the effectiveness and improve the technique of the use of viscous gels as a barrier against post-operative adhesions. We have demonstrated a clear statistically confirmed antiadhesive effect of the Hyalobarrier Gel and 4DryField ${ }^{\circledR} \mathrm{PH}$ on an experimental model of the rabbit uterus. When comparing the two preparations, the effect of the Hyalobarrier Gel was more significant. Based on the results of the experiment, both preparations can be recommended for use in routine practice. The indication depends on their availability and the surgeon's decision, both in human and veterinary medicine.

\section{Acknowledgements}

This experiment was conducted according to approved Experiment project no. 14-2021.

This work was supported by the Internal Creative Agency of the University of Veterinary Sciences Brno project number 2021ITA13.

\section{References}

Atta HM 2011: Prevention of peritoneal adhesions: a promising role for gene therapy. World J Gastroenterol 17: 5049-5058

Balbinotto RP, Trindade MR, Muller AL, Nunes AG, Da Silva R, Meyer FS, Cerski CT 2010: Experimental model of the formation of pelvic adhesions by videolaparoscopic in female rabbits. Acta Cir Bras 25: 34-36 
Blumhardt G, Haas M, Polte S 2018: Effect of 4DryField ${ }^{\mathbb{P}} \mathrm{PH}$, a novel adhesion barrier, on recurrence of intestinal adhesions after extensive visceral adhesiolysis. Case Rep Surg 2018: 9628742

Choi JS, Lee MS, Kim J, Eom MR, Jeong EJ, Lee M, Park SA, Jeong JH, Kwon SK 2021: Hyaluronic acid coating on hydrophobic tracheal scaffold enhances mesenchymal stem cell adhesion and tracheal regeneration. Tissue Eng Regen Med 18: 225-233

Coccolini F, Ansaloni L, Manfredi R, Campanati L, Poiasina E, Bertoli P, Capponi MG, Sartelli M, Di Saverio S, Cucchi M, Lazzareschi D, Pisano M, Catena F 2013: Peritoneal adhesion index (PAI): proposal of a score for the "ignored iceberg" of medicine and surgery. World J Emerg Surg 8: 6

Crha M, Lorenzová J, Urbanová L, Fichtel T, Nečas A 2008: Two techniques of intestinal wall suture in surgical treatment of ileus in dogs and the importance of omentalisation. Acta Vet Brno 77: 263-267

Dunn R, Lyman MD, Edelman PG, Campbell PK 2001: Evaluation of the SprayGel adhesion barrier in the rat cecum abrasion and rabbit uterine horn adhesion models. Fertil Steril 75: 411-416

Fortin CN, Saed GM, Diamond MP 2015: Predisposing factors to post-operative adhesion development. Hum Reprod Update 21: 536-551

Gorvy DA, Barrie Edwards G, Proudman CJ 2008: Intra-abdominal adhesions in horses: a retrospective evaluation of repeat laparotomy in 99 horses with acute gastrointestinal disease. Vet J 175: 194-201

Herrmann A, De Wilde RL 2016: Adhesions are the major cause of complications in operative gynecology. Best Pract Res Clin Obstet Gynaecol 35: 71-83

Hu C, Tang F, Wu Q, Guo B, Long WA, Ruan Y, Li L 2021: Novel trilaminar polymeric antiadhesion membrane prevents postoperative pericardial adhesion. Ann Thorac Surg 111: 184-189

Huberlant S, Fernandez H, Vieille P, Khrouf M, Ulrich D, deTayrac R, Letouzey V 2015: Application of a hyaluronic acid gel after intrauterine surgery may improve spontaneous fertility: a randomized controlled trial in New Zealand White rabbits. PLoS One 10: e0125610

Johnston MS 2005: Rabbit ovariohysterectomy. Clinician's Brief Web Site. Available at: www.cliniciansbrief. com/columns/53/rabbit-ovariohysterectomy

Kang H, Chung YS, Kim SW, Choi GJ, Kim BG, Park SW, Seok JW, Hong J 2015: Effect of temperature-sensitive poloxamer solution/gel material on pericardial adhesion prevention: supine rabbit model study mimicking cardiac surgery. PLoS One 10: e0143359

Korell M 2014: Combined hemostasis and adhesion prevention with the novel agent 4DryField ${ }^{\circledR}$ PH-initial observations. Surg Sci 5: 533-539

Krämer B, Andress J, Neis F, Hoffmann S, Brucker S, Kommoss S, Höller A 2021: Adhesion prevention after endometriosis surgery - results of a randomized, controlled clinical trial with second-look laparoscopy. Langenbecks Arch Surg, Epub ahead of print. PMID: 34036409

Lucas B, Riebau C, Mohr J, Pliske G, Walcher F, Piatek S 2021: Effect of 4DryField ${ }^{\circledR}$ PH on blood loss in hip bipolar hemiarthroplasty following intracapsular femoral neck fracture - a randomized clinical trial. BMC Musculoskelet Disord 22: 113

Mettler L 2003: Pelvic adhesions: laparoscopic approach. Ann NY Acad Sci 997: 255-268

Monnet E 2019: Laparoscopic entry techniques: What is the controversy? Vet Surg 48: O6-O14

Müller SA, Treutner KH, Jörn H, Anurov M, Oettinger AP, Schumpelick V 2005: Adhesion prevention comparing liquid and solid barriers in the rabbit uterine horn model. Eur J Obstet Gynecol Reprod Biol 120: 222-226

Müller SA, Weis C, Odermatt EK, Knaebel HP, Wente MN 2011: A hydrogel for adhesion prevention: characterization and efficacy study in a rabbit uterus model. Eur J Obstet Gynecol Reprod Biol 158: 67-71

Ntourakis D, Katsimpoulas M, Tanoglidi A, Barbatis C, Karayannacos PE, Sergentanis TN, Kostomitsopoulos N, Machairas A 2016: Adhesions and healing of intestinal anastomoses: the effect of anti-adhesion barriers. Surg Innov 23: 266-276

Osada H, Minai M, Tsunoda I, Fujii TK, Tsubata K, Satoh K 1999: The effect of hyaluronic acidcarboxymethylcellulose in reducing adhesion reformation in rabbits. J Int Med Res 27: 292-296

Peacock KE, Hurst BS, Marshburn PB, Matthews ML 2006: Effects of fibrin sealant on single-layer uterine incision closure in the New Zealand white rabbit. Fertil Steril 85: 1261-1264

Pecin M, Lipar M, Smolec O, Pirkic B, Musulin A, Kos J 2017: Changes in haematological indices following local application of interleukin-1 receptor antagonist protein after tenotomy in rabbits. Acta Vet Brno 86: 183-188

Poehnert D, Abbas M, Maegel L, Sambale F, Lavrentieva A, Kreipe HH, Klempnauer J, Winny M 2015: Evaluation of the biological tolerability of the starch-based medical device 4 DryField ${ }^{\circledR} \mathrm{PH}$ in vitro and in vivo a rat model. J Biomater Appl 30: 463-471

Poehnert D, Grethe L, Maegel L, Jonigk D, Lippmann T, Kaltenborn A, Schrem H, Klempnauer J, Winny M 2016: Evaluation of the effectiveness of peritoneal adhesion prevention devices in a rat model. Int J Med Sci 13: $524-532$

Poehnert D, Neubert L, Klempnauer J, Borchert P, Jonigk D, Winny M 2019: Comparison of adhesion prevention capabilities of the modified starch powder-based medical devices 4DryField ${ }^{\circledR} \mathrm{PH}$ and Arista ${ }^{\mathrm{TM}} \mathrm{AH}$ in the optimized peritoneal adhesion model. Int J Med Sci 16: 1350-1355

Rizzo A, Spedicato M, Mutinati M, Minoia G, Angioni S, Jirillo F, Pantaleo M, Sciorsci RL 2010: Peritoneal adhesions in human and veterinary medicine: from pathogenesis to therapy. A review. Immunopharmacol Immunotoxicol 32: 481-494 
Rudolph M, Vogt PM, Müller K, Mett TR 2019: Lymphostasis and hemostasis in body-contouring surgery using a polysaccharide based hemostat (4DryField PH). Plast Reconstr Surg Glob Open 7: e2128

Sikirica V, Bapat B, Candrilli SD, Davis KL, Wilson M, Johns A 2011: The inpatient burden of abdominal and gynecological adhesiolysis in the US. BMC Surg 11: 13

Takeuchi K, Nakazawa M, Yamazaki H, Miyagawa Y, Ito T, Ishikawa F, Metoki T 2009: Solid hyaluronic acid film and the prevention of postoperative fibrous scar formation in experimental animal eyes. Arch Ophthalmol 127: $460-464$

Tavakkoli M, Aali S, Khaledifar B, Ferns GA, Khazaei M, Fekri K, Arjmand MH 2021: The potential association between the risk of post-surgical adhesion and the activated local angiotensin II type 1 receptors: need for novel treatment strategies. Gastrointest Tumors 8: 107-114

Urbanová M, Kramářová E, Chloupek J, Najmanová M 2019: Evaluation of stress in laboratory rabbits used for teaching purposes. Acta Vet Brno 88: 249-255

van den Beukel BA, de Ree R, van Leuven S, Bakkum EA, Strik C, van Goor H, Ten Broek RPG 2017: Surgical treatment of adhesion-related chronic abdominal and pelvic pain after gynaecological and general surgery: a systematic review and meta-analysis. Hum Reprod Update 23: 276-288

Vidas Ž, Jurenec F, Karadjole T, Samardžija M, Bačić G, Beck A, Maćešić N 2018: Partial resection of the urinary bladder in swine and sheep and replacement of the resected segment by biologically inert patches. Acta Vet Brno 87: 347-350

Winny M, Maegel L, Grethe L, Lippmann T, Jonigk D, Schrem H, Kaltenborn A, Klempnauer J, Poehnert D 2016: Adhesion prevention efficacy of composite meshes Parietex ${ }^{\circledR}$, Proceed $^{\circledR}$ and 4DryField ${ }^{\circledR}$ PH covered polypropylene meshes in an IPOM rat model. Int J Med Sci 13: 936-941 
Plate V

Pánková S. et al.: Comparison ... pp. 407-414

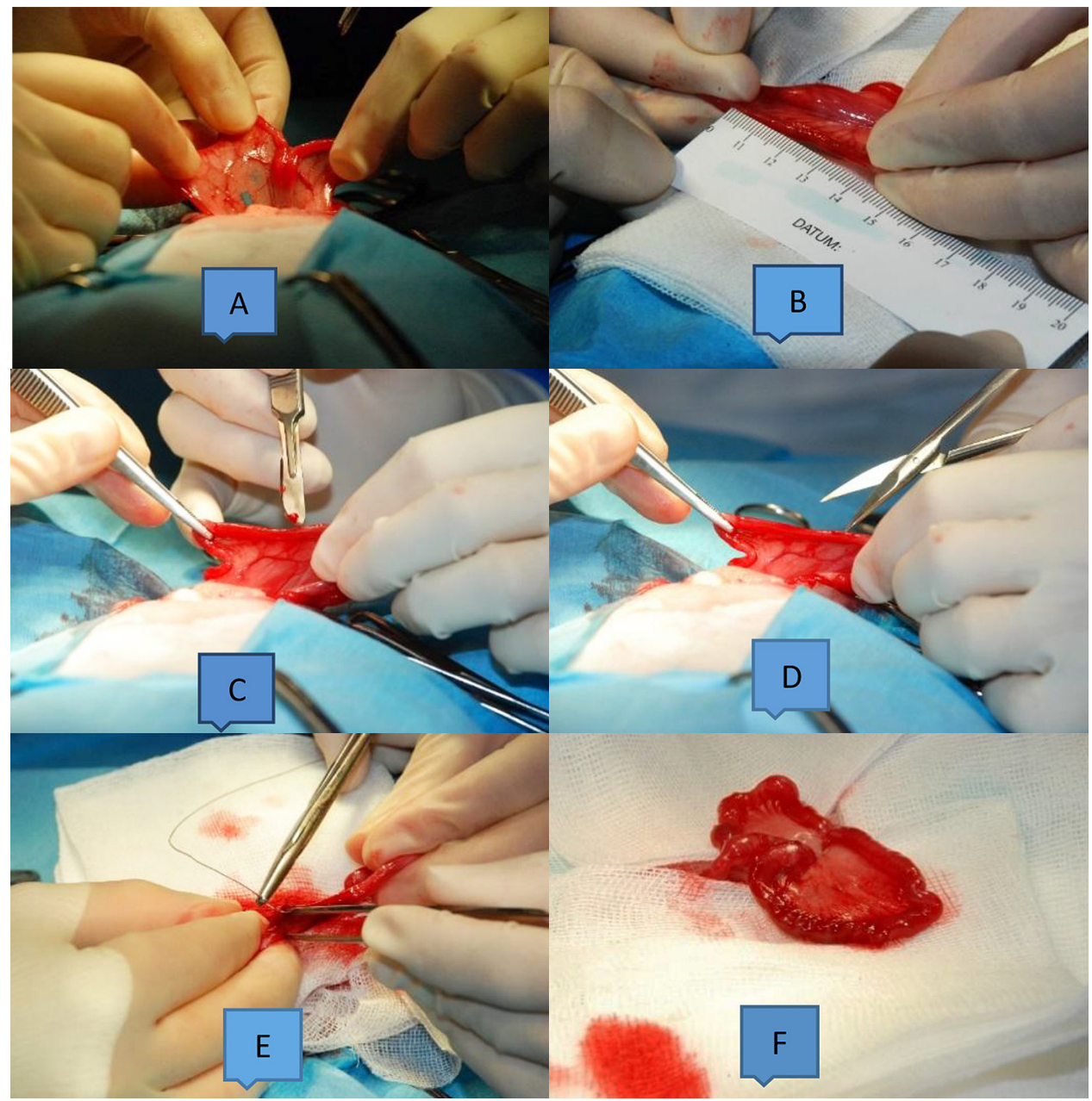

Fig. 1. A - uterus duplex - preparation of experimental model; B - myomectomy simulation - standardization; C - abrasion of the uterus with a scalpel blade; D - myomectomy simulation; E - suture of the uterus; F - experimental model - final suture 


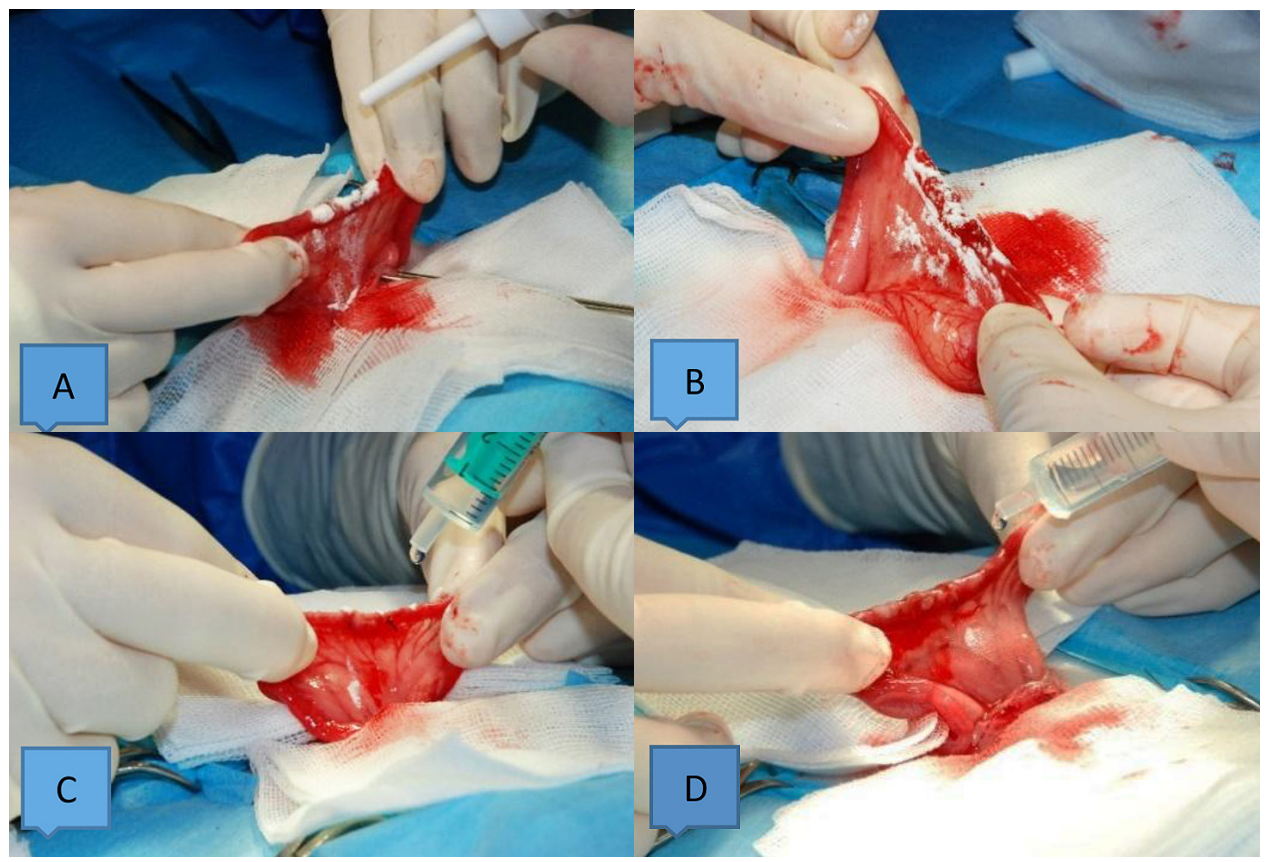

Fig. 2. A - application of solid 4DryField ${ }^{\circledR} \mathrm{PH}$ to the uterine suture; B - condition after application of the solid component; $\mathrm{C}$ - application of physiological saline solution; D - formation of a hydrogel after mixing the two components

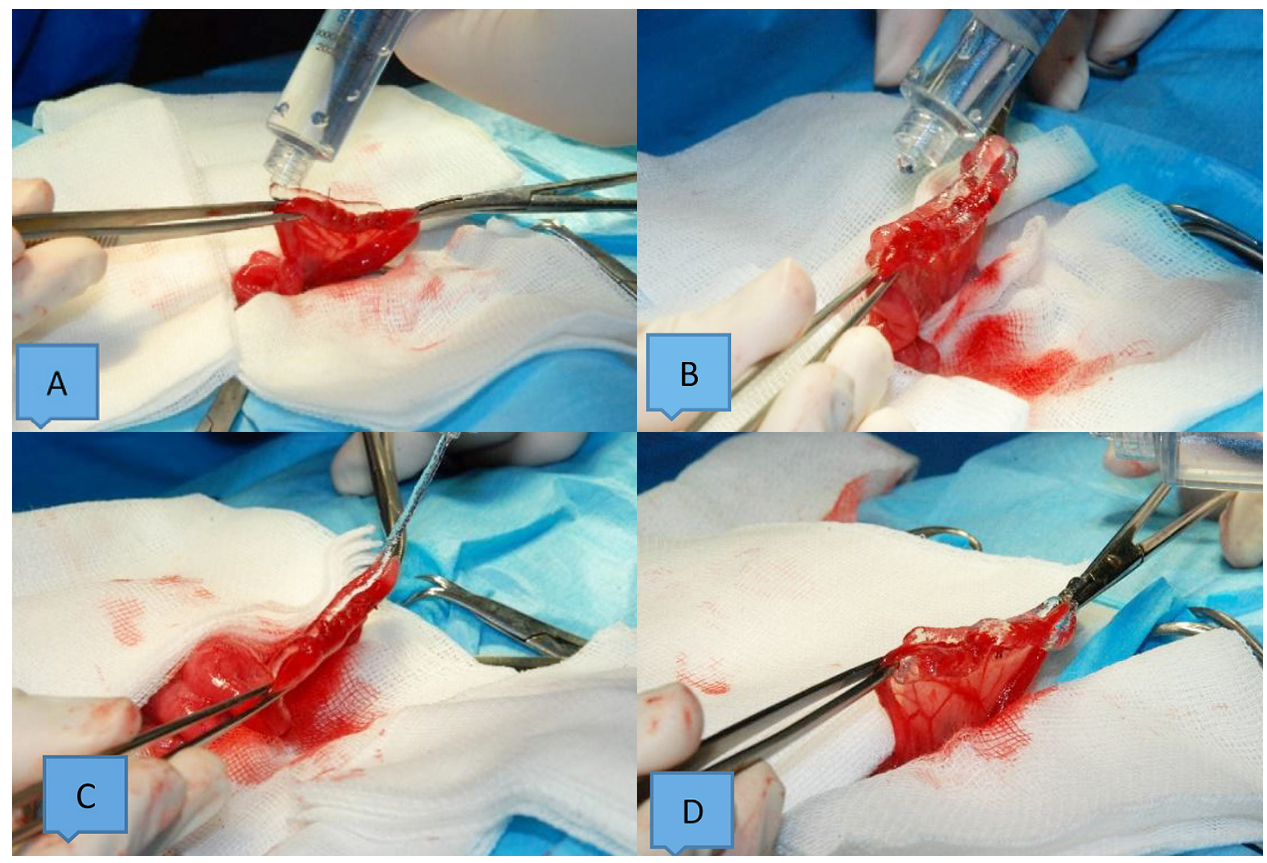

Fig 3. A, B - gradual application of the Hyalobarrier Gel; C, D - final condition after application - complex barrier 
PAISCORE $\square$ A $\square \square \mathrm{C}$

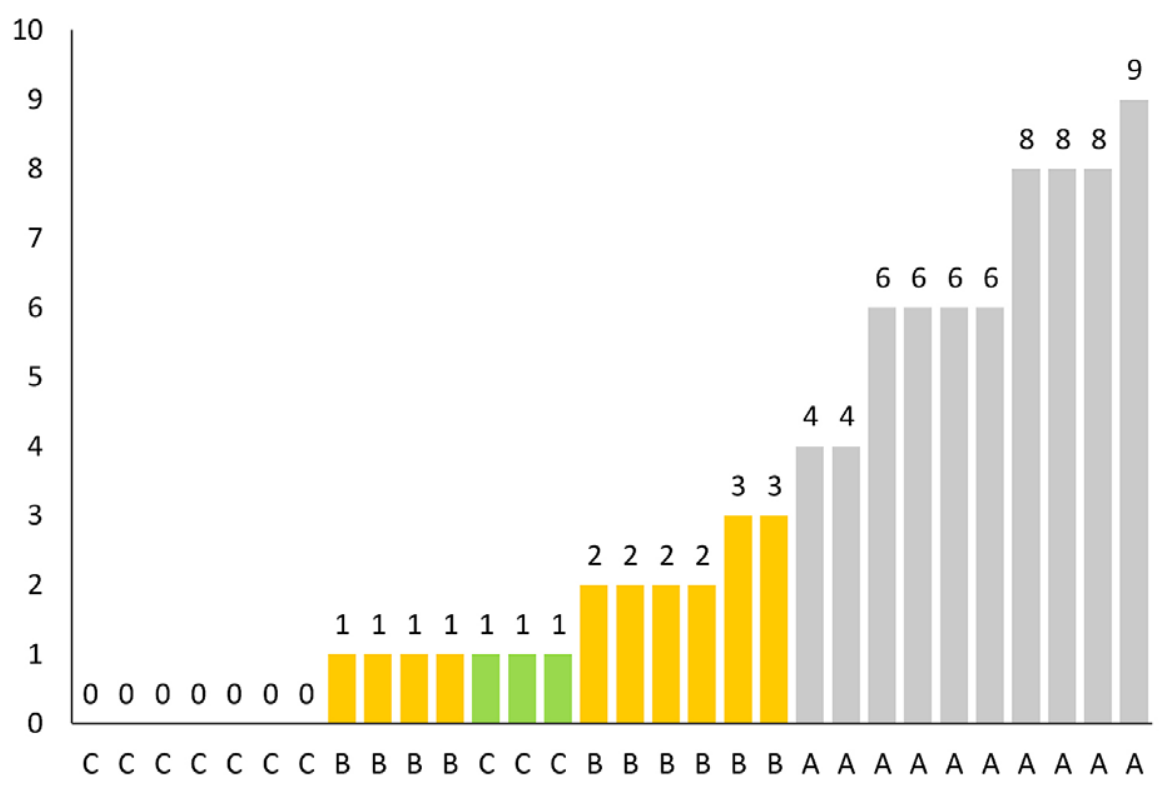

Fig. 4. Adhesion evaluation - patient's adhesion score according to the Peritoneal Adhesion Index (PAI) scoring system PAI SCORE $\square$ A $\square \square \mathrm{C}$

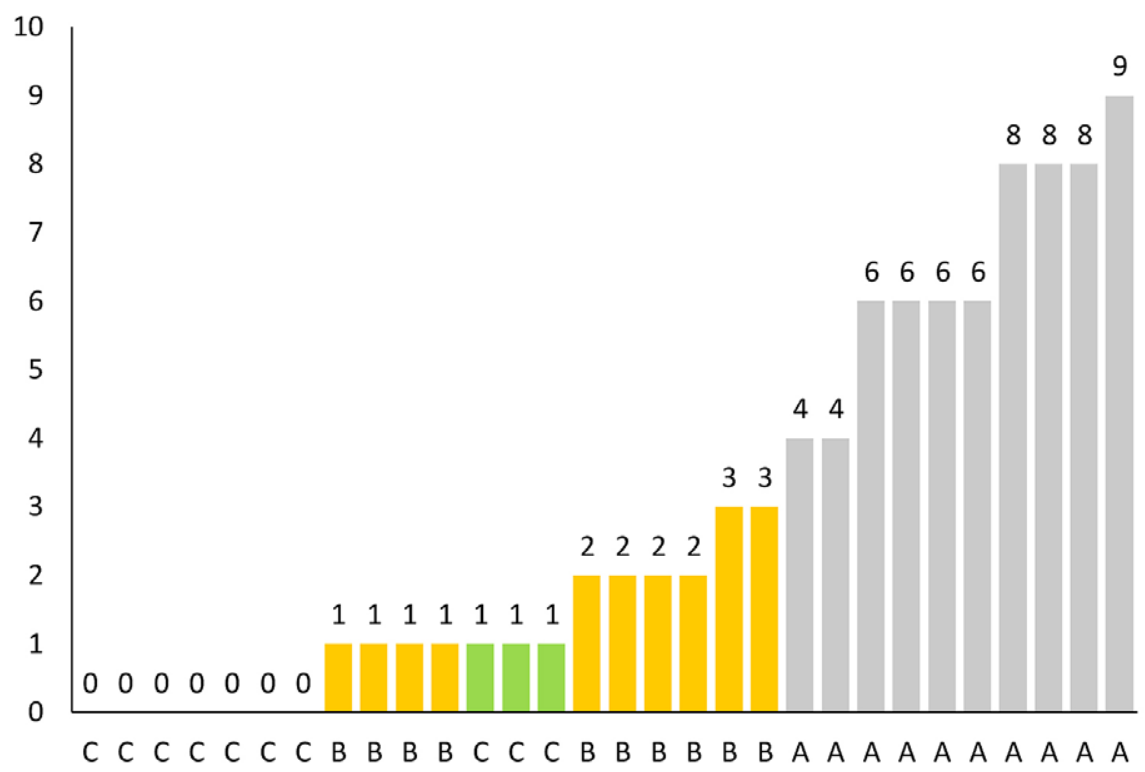

Fig. 5. Adhesion evaluation - patient's adhesion score according to More Comprehensive Adhesion Scoring Method (MCASM) scoring system 